\title{
A method for measuring total aerosol oxidative potential (OP) with the dithiothreitol (DTT) assay and comparisons between an urban and roadside site of water-soluble and total OP
}

\author{
Dong Gao ${ }^{1}$, Ting Fang ${ }^{2}$, Vishal Verma ${ }^{3}$, Linghan Zeng ${ }^{2}$, and Rodney J. Weber ${ }^{2}$ \\ ${ }^{1}$ School of Civil and Environmental Engineering, Georgia Institute of Technology, Atlanta, GA 30332, USA \\ ${ }^{2}$ School of Earth and Atmospheric Sciences, Georgia Institute of Technology, Atlanta, GA 30332, USA \\ ${ }^{3}$ School of Civil and Environmental Engineering, University of Illinois at Urbana-Champaign, Urbana, IL 61801, USA
}

Correspondence to: Rodney J. Weber (rweber@eas.gatech.edu)

Received: 13 March 2017 - Discussion started: 21 April 2017

Revised: 7 July 2017 - Accepted: 10 July 2017 - Published: 8 August 2017

\begin{abstract}
An automated analytical system was developed for measuring the oxidative potential (OP) with the dithiothreitol (DTT) assay of filter extracts that include both watersoluble and water-insoluble (solid) aerosol species. Three approaches for measuring total oxidative potential were compared. These include using methanol as the solvent with (1) and without (2) filtering the extract, followed by removing the solvent and reconstituting with water, and (3) extraction in pure water and performing the OP analysis in the extraction vial with the filter. The water extraction method (the third approach, with filter remaining in the vial) generally yielded the highest DTT responses with better precision (coefficient of variation of $1-5 \%$ ) and was correlated with a greater number of other aerosol components. Because no organic solvents were used, which must be mostly eliminated prior to DTT analysis, it was easiest to automate by modifying an automated analytical system for measuring water-soluble OP developed by Fang et al. (2015). Therefore, the third method was applied to the field study for the determination of total OP. Daily $23 \mathrm{~h}$ filter samples were collected simultaneously at a roadside (RS) and a representative urban (Georgia Tech, GT) site for two 1-month study periods, and both water-soluble (OPWS-DTT $)$ and total (OP ${ }^{\text {Total-DTT }}$ ) OP were measured. Using $\mathrm{PM}_{2.5}$ (aerodynamic diameter $<2.5 \mu \mathrm{m}$ ) high-volume samplers with quartz filters, the OPWS-DTT-to-OPTotal-DTT ratio at the urban site was $65 \%$ with a correlation coefficient $(r)$ of $0.71(N=35$; $p$ value $<0.01)$, compared to a ratio of $62 \%$ and $r=0.56$ $(N=31 ; p$ value $<0.01)$ at the roadside site. The same DTT analyses were performed, and similar results were found us-
\end{abstract}

ing particle composition monitors (flow rate of $16.7 \mathrm{~L} \mathrm{~min}^{-1}$ ) with Teflon filters. Comparison of measurements between sites showed only slightly higher levels of both OPWS-DTT and OPTotal-DTT at the RS site, indicating both OPWS-DTT and OP ${ }^{\text {Total-DTT }}$ were largely spatially homogeneous. These results are consistent with roadway emissions as sources of DTT-quantified $\mathrm{PM}_{2.5} \mathrm{OP}$ and indicate that both soluble and insoluble aerosol components contributing to OP are largely secondary.

\section{Introduction}

Exposure to ambient particulate matter (PM) is associated with adverse health effects (Atkinson et al., 2001; Li et al., 2003a; Lim et al., 2012; Pope, 1995; Pope and Dockery, 2006). The mechanisms of PM toxicity are complex and not completely understood. One view is that PM toxicity occurs through inducement of oxidative stress (Delfino et al., 2005, 2013; Nel, 2005): a state of biochemical imbalance in which the presence and formation of reactive oxygen species (ROS) in the human body overwhelms antioxidant defenses, eventually leading to various adverse health outcomes (Delfino et al., 2011; Donaldson et al., 2001; Li et al., 2003a). ROS can be either transported on inhaled particles to the air-lung interface or generated in vivo by interaction between deposited PM and physiological chemical components (Lakey et al., 2016). The ability of PM to generate ROS is defined as the oxidative potential (OP) of PM. OP integrates various 
biologically relevant properties of particles, including size, surface, and chemical composition, which may better reflect the biological response to PM exposure and consequently be more informative than PM mass, or specific PM chemical species, when attempting to link aerosols to adverse health effects.

Various methods have been developed to assess PM OP (Ayres et al., 2008; Cho et al., 2005; King and Weber, 2013; Mudway et al., 2004; Shi et al., 2003; Wang et al., 2011). The dithiothreitol (DTT) assay is used in this study to measure the OP of fine particles (i.e., OP $^{\text {DTT }}$ ). DTT acts as a surrogate of cellular reductants, such as NADH/NADPH. The goal is to mimic interactions between physiological reductants and aerosol components through a purely chemical analysis. Various aerosol components can react directly with antioxidants (reducing agents) or transfer electrons from the antioxidants to dissolved oxygen, leading to antioxidant depletion in the first case and both antioxidant depletion and ROS generation in the second. In the DTT assay, physiological reductants are represented by DTT. When this reaction is monitored under conditions of excess DTT, the DTT consumption over time is proportional to the concentration of PM redox-active species, quantified as $\mathrm{OP}^{\mathrm{DTT}}$. $\mathrm{OP}^{\mathrm{DTT}}$ per volume of air sampled has been found to correlate with biological markers, such as cellular heme oxygenase (HO-1) expression (Li et al., 2003b) and fractional exhaled nitric oxide $\left(\mathrm{FE}_{\mathrm{NO}}\right)$ in human subjects (Delfino et al., 2013; Janssen et al., 2015). Epidemiological studies have linked OPDTT to adverse health outcomes, such as asthma, rhinitis (Yang et al., 2016), asthma or wheezing, and congestive heart failure (Bates et al., 2015; Fang et al., 2016). Utilizing different measures of OP (e.g., ascorbic acid, AA; glutathione, GSH; uric acid, UA), some other studies, however, have not found links between OP and adverse health effects (Atkinson et al., 2016; Canova et al., 2014).

$\mathrm{OP}^{\mathrm{DTT}}$ of water-soluble PM components (referred to as $\mathrm{OP}^{\mathrm{WS}-\mathrm{DTT}}$ ) is the common focus of OP studies. Researchers have identified DTT-active water-soluble PM components, including humic-like substances (HULIS) (Lin and Yu, 2011; Verma et al., 2012, 2015b), oxygenated quinones (a subset of HULIS) (Cho et al., 2005; Kumagai et al., 2002), and transition metals (Charrier and Anastasio, 2012; Fang et al., 2016; Verma et al., 2015a). Water-insoluble species can also be an important fraction of the overall PM redox activity. Li et al. (2013) found that the solid particle phase was a dominant factor in the DTT-based redox activity of soot particles. Akhtar et al. (2010) found that redox-active substances could be strongly bound to solid particles and not be easily extracted by water. McWhinney et al. (2013) reported that $89-99 \%$ of the redox activity of diesel exhaust particles (DEPs) were water-insoluble and not extractable by moderately polar (methanol) and nonpolar (dichloromethane) organic solvents. Daher et al. (2011) reported the highest intrinsic $\mathrm{OP}^{\mathrm{DTT}}$ for particle collection with a BioSampler, which was considered most efficient in capturing both the soluble and insoluble PM species. Including the contribution of water-insoluble species in the OP assessment would be closer to actual PM exposure. A measure of both watersoluble and water-insoluble OP would be useful to elucidate the relative risks of water-soluble versus water-insoluble OPinduced health risks for specific health end points, such as respiratory versus cardiovascular dysfunction.

Several PM extraction methods have been used to assess the OP of water-insoluble PM. A common approach is to extract water-insoluble species in organic solvents, such as methanol and dichloromethane. Verma et al. (2012) found $\mathrm{OP}^{\mathrm{DTT}}$ (expressed per microgram of PM mass) of filtered methanol extracts to be correlated with water-insoluble organic carbon (OC) and elemental carbon (EC, $N=8$ ). The DTT assay response for the methanol extracts was significantly higher than that for the water extracts, with a methanol-to-water $\mathrm{OP}^{\mathrm{DTT}}$ ratio of $1.6 \pm 0.4$. Yang et al. (2014) compared OP ${ }^{\mathrm{DTT}}$ of ambient PM with two extraction methods for Teflon filters: methanol extraction without filtering and water extraction. They found that the methanol extracts were more DTT-reactive (expressed per cubic meter of sampled volume) than the water extracts. In this method, removal of organic solvent by evaporation was necessary prior to the DTT assay, which can result in the loss of labile redox-active PM species, such as semi-volatile organic compounds. Instead of attempting to dissolve water-insoluble species in various solvents, other studies perform the assay in the extraction liquid without filtration, retaining the insoluble particles in the DTT reaction solution. McWhinney et al. (2013) measured total redox activity of DEPs using particle suspensions that were obtained by a water extraction procedure with the filter removed after extraction. Whereas Charrier et al. (2016) performed the DTT assay on the extraction liquid that still contained the filter. Daher et al. (2011) collected particles directly into water with a BioSampler and performed the DTT analysis without filtration.

In this study, we assess techniques for quantifying the overall oxidative potential of ambient particles and determine the relative contribution from water-soluble and waterinsoluble components to PM OP by contrasting measurements from different sites. This was accomplished by conducting the DTT assay on samples extracted by three different methods. The goal was to develop a system for measuring both soluble and total $\mathrm{OP}^{\mathrm{DTT}}$ (insoluble $\mathrm{OP}^{\mathrm{DTT}}$ by difference) fractions to allow studies on the health effects of soluble (Bates et al., 2015) versus insoluble PM OP.

\section{Experimental methods}

\subsection{Sampling methods and locations}

Measurements were made at two contrasting sampling sites: Georgia Tech (GT) and roadside (RS). The GT site was situated on the rooftop of the Ford ES\&T building on the campus of Georgia Tech about $30 \mathrm{~m}$ above ground level and approx- 
imately $420 \mathrm{~m}$ from the roadside site. (A map of the sites is provided in Fig. S1 in Supplement.) The GT site is assumed to be representative of the urban Atlanta environment. The RS site is adjacent (within $3 \mathrm{~m}$ ) to a heavily trafficked interstate freeway (I-85/75) with an annual average daily traffic count of 382000 vehicles in 2015 (GDOT, 2017; station ID 1215482). Heavy-duty trucks are restricted, resulting in predominantly light-duty gasoline vehicle traffic (non-heavyduty truck traffic nominally $95 \%$; GDOT, 2013).

Measurements were undertaken during two different periods using different particle filter collection systems. A highvolume (HiVol) sampler (Thermo Anderson, nominal flow rate of $1.13 \mathrm{~m}^{3} \mathrm{~min}^{-1}, \mathrm{PM}_{2.5}$ impactor) was set up at each site to collect ambient fine particles simultaneously from 21 April to 30 May 2016. Fine particles were collected with prebaked $8 \times 10$ in. quartz filters (Pallflex Tissuquartz, Pall Life Sciences) for 23 h (11:00-10:00 LT the next day). The HiVol quartz filters were wrapped in prebaked aluminum foil immediately after collection and stored at $-18^{\circ} \mathrm{C}$ until analyses. The bias between the two HiVol samplers was assessed by running them side by side at GT for 9 days. The measurements were within $10 \%$ for both water-soluble $\mathrm{OP}^{\text {DTT }}\left(\mathrm{OP}^{\mathrm{WS}-\mathrm{DTT}}\right)$ and total OP ${ }^{\mathrm{DTT}}\left(\mathrm{OP}^{\text {Total-DTT }}\right)$ (obtained by method 3, described below) (Fig. S2). In Sect. 3.4, OP data from HiVol 1 were adjusted to match HiVol 2 based on the orthogonal linear regression from this comparison. The factors used to convert OP from HiVol 1 to HiVol 2 were 1.00 and 1.10 for OP ${ }^{\text {WS-DTT }}$ and OP ${ }^{\text {Total-DTT }}$, respectively.

Zefluor PTFE membrane filters (diameter $47 \mathrm{~mm}$, $2 \mu \mathrm{m}$ pore size, Pall Life Sciences) were used as well for simultaneous $\mathrm{PM}_{2.5}$ sample collection from 26 July to 21 August 2016 using particle composition monitors (PCMs, 16.7 $\mathrm{L} \mathrm{min}^{-1}, \mathrm{PM}_{2.5}$ URG cyclone, undenuded). Two PCMs were installed at each site to obtain two Teflon samples; one was used for OP ${ }^{\text {WS-DTT }}$ and the other for OP ${ }^{\text {Total-DTT }}$ analysis. Similar to the HiVol filter sampling, after $23 \mathrm{~h}$ collection, the PCM Teflon filters were placed into Petri dishes and stored at $-18^{\circ} \mathrm{C}$.

\subsection{Measurements of PM oxidative potential}

OP analyses were performed on both HiVol quartz and PCM Teflon filters. The DTT assay followed the protocol developed by Cho et al. (2005). All OP analyses on HiVol quartz filters were done immediately after collection; OP measurements on Teflon filters were completed within 1 month after collection.

\subsubsection{OP ${ }^{\mathrm{WS}-\mathrm{DTT}}$ analysis}

One circular punch (diameter of 1 in.) from the HiVol quartz filter was extracted in $4.9 \mathrm{~mL}$ of deionized water (DI, $>18 \mathrm{M} \Omega \mathrm{cm}^{-1}$ ) in a sterile polypropylene centrifuge tube (VWR International LLC, Suwanee, GA, USA) via $30 \mathrm{~min}$ sonication. Considering the potential for radical formation during the sonication process (Miljevic et al., 2014), experiments using sonication versus shaking were done. Little difference observed in OP for sonication versus shaking indicated negligible bias in OP ${ }^{\text {WS-DTT }}$ measurement due to sonication; see Fig. S3. The extract was then filtered through $0.45 \mu \mathrm{m}$ PTFE syringe filters (Fisherbrand, Fisher Scientific) to remove insoluble material. The filtered $\mathrm{PM}$ water extract was analyzed using a semi-automated system (OPWS-DTT system) developed by Fang et al. (2015) where all chemical reagents and reaction mixtures were mixed and transferred by two programmable syringe pumps. Briefly, $3.5 \mathrm{~mL}$ water extract is incubated with $0.5 \mathrm{~mL}$ of $1 \mathrm{mM}$ DTT and $1 \mathrm{~mL}$ potassium phosphate buffer (K-buffer; $\mathrm{pH}=7.4$ ) in a single incubation vial (IV) at $37^{\circ} \mathrm{C}$. At designated time points ( 0 , $4,13,23,32,41 \mathrm{~min})$, an aliquot $(100 \mu \mathrm{L})$ of this mixture is transferred to another vial (reaction vial, RV) and mixed with trichloroacetic acid (TCA) to quench the reaction. Tris buffer $(\mathrm{pH}=8.9)$ and 5,5'-dithiobis-(2-nitrobenzoic acid) (DTNB) are then added to form a colored product which absorbs light at $412 \mathrm{~nm}$. The final mixture is pushed through a $10 \mathrm{~cm}$ path length liquid waveguide capillary cell (LWCC), and the absorbance at $412 \mathrm{~nm}$ is detected and recorded by an online UV-visible spectrophotometer. The DTT concentration at each time point is quantified based on the absorbance calibration curve, which had previously been determined from standard DTT solutions also containing TCA, tris buffer, and DTNB. The DTT consumption rates are then determined by applying linear regression to the observed DTT concentration versus time. The final OP results are calculated by subtracting a blank value from the sample and normalized by the volume of air that passed through the filter (of 1 in. diameter punch size), expressed as nanomoles of DTT per minute (nmolDTT $\mathrm{min}^{-1}$ ) per sampled air volume (OP ${ }^{\text {WS-DTT }} \mathrm{m}^{-3}$; if not explicitly stated, OPWS-DTT is OP ${ }^{\text {WS-DTT }} \mathrm{m}^{-3}$ ) to provide a measure of atmospheric levels of water-soluble aerosol OP. The DTT consumption rates of multiple blanks for quartz filters $(N=42)$ were stable with a mean $\pm 1 \sigma$ of $0.33 \pm 0.07 \mathrm{nmol} \mathrm{min}{ }^{-1}$. Since DTT is a relatively unstable compound, it can react with dissolved oxygen in the liquid in the absence of particles (Kumagai et al., 2002), resulting in OP response in blanks. The blank OP values are also due to trace levels of contaminants on the filter, in the DI, and introduced during sample preparation. 9,10-Phenanthrenequinone (PQN) is used as a positive control throughout the analysis to evaluate the stability of the analytical system.

Water extraction was also performed on the PCM Teflon filters. Each of the two Teflon filters collected simultaneously at each site was cut in half. One half of each filter was combined and immersed in $4.9 \mathrm{~mL}$ DI in a beaker and sonicated for $30 \mathrm{~min}$. The water extract was then filtered, and OP ${ }^{\text {WS-DTT }}$ determined using the automated system. DTT analytical processing was exactly the same as that for quartz filters described above. The other filter halves were stored in a freezer until OP${ }^{\text {Total-DTT }}$ analysis. This analysis approach re- 


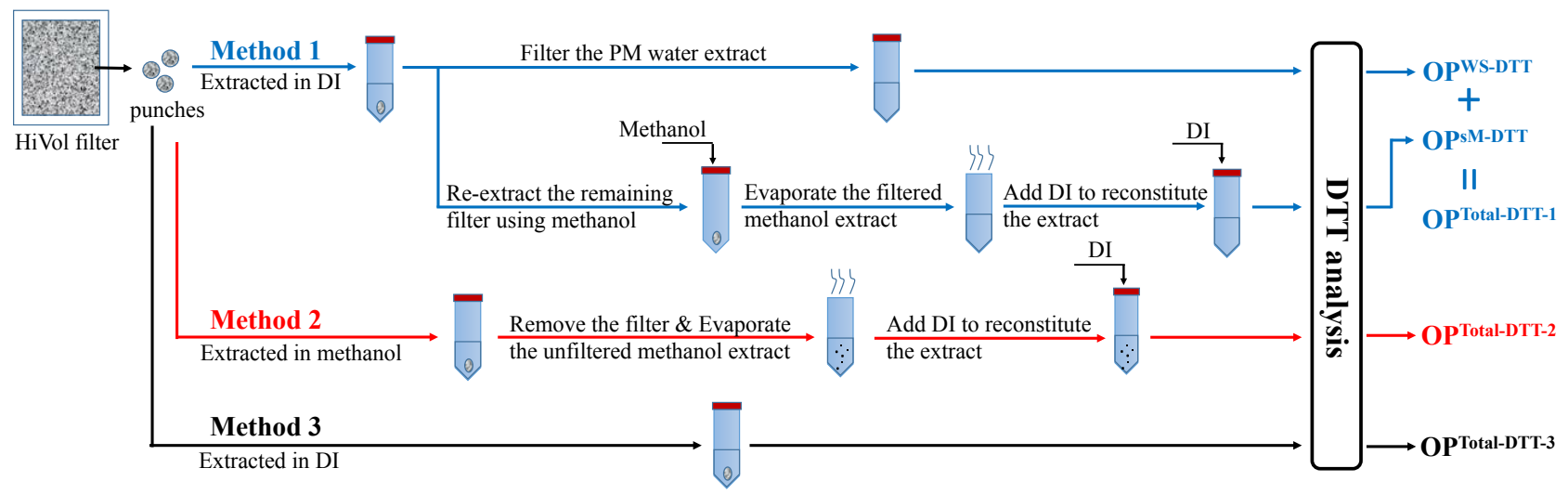

Figure 1. Analytical scheme for three sample extraction methods to determine total OP with the DTT assay (OP ${ }^{\text {Total-DTT }}$ ).

moved any potential biases associated with the separate filter collection systems at each site. Sample flow rates were measured at the beginning and end of sampling for each filter system, and the overall average was used to calculate OP ${ }^{\text {WS-DTT }}$ per cubic meter. Field blanks were also tested in the same manner and had an average slope plus or minus standard deviation of $0.35 \pm 0.08 \mathrm{nmol} \mathrm{min}^{-1}$ (mean $\pm 1 \sigma, N=18$ ).

\subsubsection{OP OPtal-DTT $^{\text {Tnalysis }}$}

\section{Sample extraction and preparation}

To assess methods for characterizing OP ${ }^{\text {Total-DTT }}$, we used three different methods of sample preparation using the HiVol quartz filters. Sample preparation schemes are illustrated in Fig. 1. Multiple method analysis was done only on HiVol filters since there was insufficient mass collected to compare different methodologies using the PCM Teflon samples.

Method 1 consisted of two steps: water extraction and sequential methanol extraction. A 1 in. circular punch taken from the HiVol quartz filter was extracted in $4.9 \mathrm{~mL}$ DI via $30 \mathrm{~min}$ sonication. The water extract was then filtered using a $0.45 \mu \mathrm{m}$ PTFE syringe filter. This step was the same as the measurement of OPWS-DTT. The water-extracted filter punch was retained in the vial, dried in room air, and re-extracted using methanol (HPLC grade) via $30 \mathrm{~min}$ sonication. The methanol extract was also filtered through a syringe filter $(0.45 \mu \mathrm{m}$ PTFE) and then concentrated to about $200 \mu \mathrm{L}$ using high-purity nitrogen gently blown into the vial above the liquid surface. DI was added into the vial to reconstitute the small aliquot of remaining methanol liquid to $4.9 \mathrm{~mL}$ of solution. The reconstituted extract was stirred using a vortex mixer $\left(\mathrm{VWR}^{\circledR}\right.$ Analog Vortex Mixer, 300$3200 \mathrm{rpm}$ ) for $10 \mathrm{~s}$ to resuspend any particles deposited on the walls of the vial during methanol blow-down. The purpose of the sequential and filtered methanol extraction was to assess if water-insoluble species could be dissolved by methanol as a way of quantifying the water-insoluble $\mathrm{OP}^{\mathrm{DTT}}$ through a contrast to methods that retained solid particles (discussed next). As methanol is less polar than water, it may dissolve most of the water-insoluble organic species in addition to some water-soluble compounds. However, since the solid-phase material in the extract may have been removed by filtering the extract, this method will not include DTTactive species that cannot be separated from a solid particle and is therefore removed by the syringe filter. The determination of $\mathrm{OP}^{\mathrm{DTT}}$ for both water extract (OPWS-DTT $)$ and sequential DI-reconstituted methanol extract $\left(\mathrm{OP}^{\mathrm{sM}-\mathrm{DTT}}\right)$ was conducted using the OP ${ }^{\text {WS-DTT }}$ analytical system since all extracts had been filtered, avoiding any plugging or contamination issues in the analytical system by solid particles. The sum of OP ${ }^{\text {WS-DTT }}$ and OP ${ }^{\text {sM-DTT }}$ is the total redox activity obtained by method 1 , which will be denoted

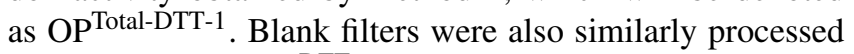
and analyzed for $\mathrm{OP}^{\mathrm{DTT}}$, producing blank values of $0.33 \pm$ $0.07 \mathrm{nmol} \mathrm{min}^{-1}$ (mean $\pm 1 \sigma, N=42$ ) for OPWS-DTT and $0.43 \pm 0.09 \mathrm{nmol} \mathrm{min}^{-1}$ (mean $\pm 1 \sigma, N=18$ ) for OP ${ }^{\text {sM-DTT }}$. This method was used in the Southeastern Center for Air Pollution and Epidemiology (SCAPE) study, so a substantial data set $(N=198)$ exists on OP ${ }^{\text {SM-DTT }}$.

Method 2 is similar to the methanol extraction by Yang et al. (2014). The filter punch was extracted in methanol via 30 min sonication. After extraction, the filter punch was removed from the vial. The methanol extract was not filtered so that the methanol-insoluble components were also retained and would possibly participate in the subsequent DTT reaction. The methanol suspension was blown down to nominally $200 \mu \mathrm{L}$ using nitrogen gas and reconstituted to $4.9 \mathrm{~mL}$ with DI. The reconstituted extract was stirred for $10 \mathrm{~s}$ using a vortex mixer in an attempt to resuspend particles deposited on vial walls. Due to the presence of solid material in the extract, such as quartz filter fibers released by sonication, the OPWS-DTT system could not be utilized. Instead, a modified automated system was needed to measure the OP of this aqueous suspension, discussed below. The $\mathrm{OP}^{\mathrm{DTT}}$ of PM sample extracted in this manner is referred 


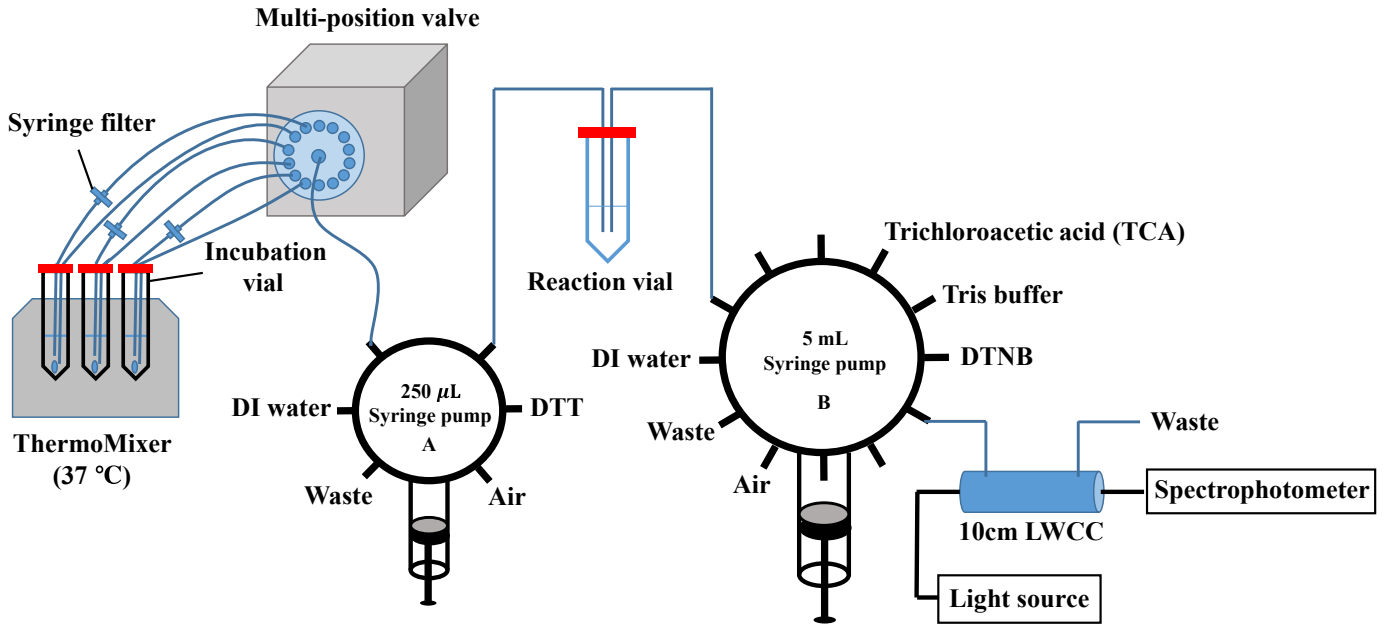

Figure 2. Automated system setup for measuring OPDTT-Total. The assay is performed in the vial containing the filter sample and extraction water, which had been sonicated. The assay is filtered just prior to analysis in the liquid wave guide capillary cell (LWCC).

to as $\mathrm{OP}^{\text {Total-DTT-2 }}$. The blank value for this method was $0.42 \pm 0.13 \mathrm{nmol} \mathrm{min}^{-1}$ (mean $\pm 1 \sigma, N=18$ ).

Method 3 is the easiest to perform among the three methods in terms of sample preparation (Fig. 1). In this case the circular filter punch was immersed in the mixture of $4.9 \mathrm{~mL} \mathrm{DI}$ and $1.4 \mathrm{~mL} \mathrm{~K}$-buffer in a sterile polypropylene centrifuge tube, followed by $30 \mathrm{~min}$ sonication. The DTT assay was then performed directly in the vial with the filter punch present using the modified automated system discussed below. Some DTT-active species may be strongly absorbed to the filter surface so that they are not extractable into water. But in method 3, since the whole filter is suspended in DTT solution, these DTT-active species may participate in the reaction with DTT. In the study of Charrier et al. (2016), where DTT was also directly incubated with the PM filter, an alcohol, 2,2,2-trifluoroethanol, was added to the extraction solvent to facilitate removal of particles from the filter substrate. We tested adding small amounts of methanol (up to $10 \%$ of total extraction volume) into the extraction solvent to investigate if methanol would expose more solid aerosol for reaction with DTT, which would be observed as an increase in DTT response. The test results are given in Fig. S4 and show that the added methanol had negligible effects on the final $\mathrm{OP}^{\mathrm{DTT}}$ measured; therefore, only DI was used for extraction in this method. The OPDTT obtained in this way is referred to as OP ${ }^{\text {Total-DTT-3 }}$. Sonicationversus-shaking tests were also performed in method 3 , and the results (Fig. S5) show little effect of sonication on OPTotal-DTT-3 measurements. Only method 3 was used for the OP ${ }^{\text {Total-DTT }}$ determination of Teflon filters. Multiple blanks were processed similarly with DTT consumption rates of $0.37 \pm 0.06 \mathrm{nmol} \mathrm{min}^{-1}$ (mean $\pm 1 \sigma, N=18$ ) for quartz filters and $0.43 \pm 0.04 \mathrm{nmol} \mathrm{min}^{-1}$ (mean $\pm 1 \sigma, N=18$ ) for Teflon filters.

\section{Automated system for OP ${ }^{\text {Total-DTT }}$ measurements}

A modified automated analytical system for OP ${ }^{\text {Total-DTT }}$ was developed by modifying the OPWS-DTT system of Fang et al. (2015) for analysis of filters extracted using methods 2 and 3. A schematic is shown in Fig. 2. In this approach the sample extraction vial containing the suspension or suspension plus filter that had gone through method 2 or 3 extraction is placed in the thermal mixer, prior to which $1.4 \mathrm{~mL} \mathrm{~K}$-buffer had been loaded manually. In this case, each sample vial is used as an incubation vial directly, continuously shaken, and maintained at $37^{\circ} \mathrm{C}$ via a ThermoMixer $\left(\mathrm{VWR}^{\circledR} \mathrm{Cool}-\right.$ ing Thermal Shake Touch; rotational frequency of $400 \mathrm{rpm}$, temperature of $\left.(37 \pm 0.5){ }^{\circ} \mathrm{C}\right)$. Two PEEK tubes (PEEK Tubing Green $1 / 16$ in. OD $\times 0.030$ in. ID), which are connected to a 14-port multi-position valve (Valco Instrument Co. Inc. (VICI), USA), are inserted into each incubation vial, with one tube having an in-line syringe filter $(0.45 \mu \mathrm{m}$ polypropylene, filter media, Whatman) and the other not. For each run, $0.7 \mathrm{~mL}$ DTT $(1 \mathrm{mM})$ is loaded into the incubation vial through the tubing without in-line filter via the programmable syringe pump A (see Fig. 2). Air is then pumped into the incubation vial to thoroughly mix. In the mixture, DTT is presumably oxidized with the catalytic assistance of both water-soluble and water-insoluble DTT-active species associated with the PM collected on the HiVol quartz or PCM Teflon filter. After mixing, the multi-position valve is switched so that the syringe can withdraw an aliquot of sample through the filter, at a low speed so as not to form air bubbles by cavitation. At designated time intervals $(13,30$, $48,65,82 \mathrm{~min}$ ), the aliquot is withdrawn through the in-line filter, transferred to the RV and mixed with TCA preloaded in the vial by pump B. The DTT concentration is then determined following the same steps as for the OPWS-DTT system (Fang et al., 2015). A total of five data points of remain- 
ing DTT concentrations versus time are generated and used for the final OP ${ }^{\mathrm{DTT}}$ determination. After finishing the DTT analysis of each sample, the system is thoroughly cleaned by flushing with DI to remove the residual liquid left in the various tubing, reaction vial, pump syringes, and LWCC. Following the flushing, the 14-port multi-position valve is switched to the next sample for analysis. Due to the slow piston motions in liquid transfer from IV to RV, it generally takes $1.5 \mathrm{~h}$ for $\mathrm{OP}^{\text {Total-DTT }}$ system to analyze one sample, compared with $1 \mathrm{~h}$ of analysis time of OPWS-DTT. The OP ${ }^{\text {Total-DTT }}$ system, like the OP ${ }^{W S-D T T}$ system, can operate unattended and be monitored remotely to analyze, at least, seven filters. (This is limited by the 14 channels of the multi-position valve in Fig. 2.) To avoid contamination from the insoluble material captured in the in-line syringe filter, the syringe filter is replaced after each sample run. The automated system is cleaned every 4 weeks of continued operation by flushing at least three times with methanol, followed by four times with DI.

\subsection{Other chemical analysis}

A number of other aerosol components were analyzed on the HiVol quartz filters to assess the various methods of measuring $\mathrm{OP}^{\text {Total-DTT }}$. Carbon analysis (EC and OC) was performed on a $1.5 \mathrm{~cm}^{2}$ punch from the quartz filters using Interagency Monitoring of Protected Visual Environments (IMPROVE) thermal optical reflectance (TOR) protocol (Chow et al., 1993).

Total and water-soluble metals were determined by inductively coupled plasma mass spectrometry (ICP-MS) (Agilent 7500a series, Agilent Technologies, Inc., CA, USA) using EPA method 6020, again from sections of the same HiVol quartz filters. The elements of interest included species that possibly play a role in $\mathrm{ROS}$ generation $(\mathrm{Fe}, \mathrm{Mn}, \mathrm{Cu}$; Schoonen et al., 2006) and K, a marker of biomass burning (Artaxo et al., 1994). For the determination of concentrations of total metals, acid digestion was carried out on a $1.5 \mathrm{~cm}^{2}$ filter punch using nitro-hydrochloric acid $\left(\mathrm{HNO}_{3}+3 \mathrm{HCl}\right)$. The acid-digested sample was then diluted in DI, filtered with a $0.45 \mu \mathrm{m}$ PTFE syringe filter. No digestion was required prior to the analysis of water-soluble metals. A $1.5 \mathrm{~cm}^{2}$ punch from the quartz filter was sonicated in DI for $30 \mathrm{~min}$. After sonication, the extract was filtered using a $0.45 \mu \mathrm{m}$ PTFE syringe filter and then acid-preserved by adding concentrated nitric acid $(70 \%)$ to a final concentration of $2 \%(v / v)$. A set of mixed calibration standard solutions were prepared by diluting the stock standard solutions and treated with the same procedures as samples. Internal standards, including lithium $\left({ }^{6} \mathrm{Li}\right)$ and scandium $\left({ }^{45} \mathrm{Sc}\right)$, were added to all calibration standards and samples to monitor instrumental drift. DI blank and field blank which consist of the same concentrations of acid and internal standards were used to monitor for possible contamination resulting from the sample preparation procedures. This was critical since in this case no special care was taken to pre-acid-wash the quartz filters or syringe filters used in the water-soluble metal analysis. The method detection limits are defined here as 3 times the standard deviation of blanks, which for water-soluble metal method were $0.03 \mathrm{mgL}^{-1}$ for $\mathrm{K}, 0.00007 \mathrm{mgL}^{-1}$ for $\mathrm{Mn}$, $0.009 \mathrm{mg} \mathrm{L}^{-1}$ for $\mathrm{Fe}$, and $0.0002 \mathrm{mg} \mathrm{L}^{-1}$ for $\mathrm{Cu}$; for the total metal method they were $0.03 \mathrm{mg} \mathrm{L}^{-1}$ for $\mathrm{K}, 0.0002 \mathrm{mg} \mathrm{L}^{-1}$ for $\mathrm{Mn}, 0.02 \mathrm{mg} \mathrm{L}^{-1}$ for $\mathrm{Fe}$, and $0.002 \mathrm{mg} \mathrm{L}^{-1}$ for $\mathrm{Cu}$.

\subsection{Data analysis}

Linear regression was applied to the experimental data in order to assess relationships between measurements. Since the data were normally distributed (shown in Fig. S6), the Pearson correlation coefficients were calculated to further demonstrate the strength and the direction of a linear relationship between two measurements. A correlation coefficient greater than 0.7 with a low $p$ value $(<0.05)$ was generally described as strong.

The paired $t$ tests were used to determine whether there was a significant difference in OP measurements between two methods. Each OP ${ }^{\text {Total-DTT }}$ was measured using three methods, resulting in pairs of observations. The null hypothesis of the paired $t$ test assumed that the mean difference between the paired observations was zero. The $p$ value of the test gave the probability of observing the test results under the null hypothesis; $p$ values less than 0.05 rejected the null hypothesis at the $5 \%$ significance level.

The $F$ tests in one-way analysis of variance (ANOVA) were employed to evaluate the impact of filter type (i.e., quartz versus Teflon filters) on the PM OP measurements for a given site. The $F$ statistic is the ratio of between-group variability to within-group variability, which followed an $F$ distribution under the null hypothesis. In this paper, the null hypothesis assumed that there was no significant OP difference between Teflon and quartz filters. If the $F$ calculated from the data were smaller than the critical $F$ value of the $F$ distribution for significance level $\alpha=0.05$, then the null hypothesis would be true with $95 \%$ confidence.

The spatial variability of OP (Table S6 in Supplement) was assessed by the coefficients of divergence (COD) (Pinto et al., 2004; Wilson et al., 2005):

$\mathrm{COD}=\sqrt{\frac{1}{N} \sum_{i=1}^{N}\left(\frac{c_{i j}-c_{i k}}{c_{i j}+c_{i k}}\right)^{2}}$,

where $c_{i j}$ and $c_{i k}$ were OPWS-DTT or OP ${ }^{\text {Total-DTT }}$ measured at site $j$ and $k$, respectively, and $N$ was the number of observations. A COD close to 0 implied spatial uniformity, while a value approaching unity indicated absolute heterogeneity.

\section{Results and discussion}

First we discuss the performance of the automated system for measuring OPTotal-DTT where filters were extracted by 
method 3 (Fig. 1), and then we compare the results of the three differing methods for measuring $\mathrm{OP}^{\text {Total-DTT }}$ at the two sampling sites. The system performance was assessed by only method 3 since these samples were easiest to prepare, and this is the final approach of the three methods tested that was extensively utilized. Finally, we compare results from method 3 using quartz filters to a later study using Teflon filters. All OPDTT results were blank-corrected.

\subsection{Automated OP ${ }^{\text {Total-DTT }}$ system performance}

The performance of the automated system was assessed in terms of the system response, accuracy, and precision. PQN, a quinone that has been identified to be DTT-active (Kumagai et al., 2002) and often utilized as a positive control (Fang et al., 2015), was used to test the system response. A highly linear relationship $\left(R^{2}=0.97\right)$ was found between PQN concentration in the incubation vial and the DTT consumption rate measured by the system (shown in Fig. 3). This linear relationship is consistent with the results shown in Fang et al. (2015) and Charrier et al. (2016).

The accuracy of measurements given by the OP ${ }^{\text {Total-DTT }}$ system was further assessed by comparing the DTT consumption rate obtained by the system to that following the manual DTT analysis approach of Cho et al. (2005). Seven PQN solutions of various concentrations were tested by both the automated system and manual approach. As shown in Fig. 4, a bivariate linear regression was applied and yielded a slope near unity $(0.99 \pm 0.06)$, intercept close to $0(0.04 \pm$ 0.04 ), and correlation of determination $\left(R^{2}\right)$ of 0.98 . For further validation, five ambient samples, which in this case would include insoluble species, were extracted by method 3 and analyzed using both the automated and manual methods (see Fig. S7). The ratio of automated to manual DTT consumption rate was $0.98 \pm 0.05$. These tests illustrate the valid-

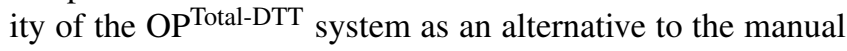
DTT assay.

To assess the precision of the automated OP ${ }^{\text {Total-DTT }}$ system, the DTT consumption rates of identical concentrations of several PQN solutions were repeatedly measured. The OP ${ }^{\text {Total-DTT }}$ system produced consistent results for the PQN replicates (blank-corrected DTT consumption rate of $0.76 \pm 0.05 \mathrm{nmol} \mathrm{min}^{-1}$ for $0.21 \mathrm{nmol} \mathrm{mL}^{-1}$ of $\mathrm{PQN}$ in the incubation vial; coefficient of variation, $\mathrm{CV}=6 \% ; N=7$ ), suggesting good precision of the system. We conclude that most variability in the analysis of samples will be introduced in the extraction process and not the DTT analysis.

\subsection{Precisions of various methods}

To test the precision of the complete approach for measurement of OP ${ }^{\text {Total-DTT }}$ (i.e., extraction and analysis), measurements of OP${ }^{\text {Total-DTT }}$ were repeated three times using three separate punches from the same HiVol quartz filter. This was done for all three OP${ }^{\text {Total-DTT }}$ methods. The CV for replicates

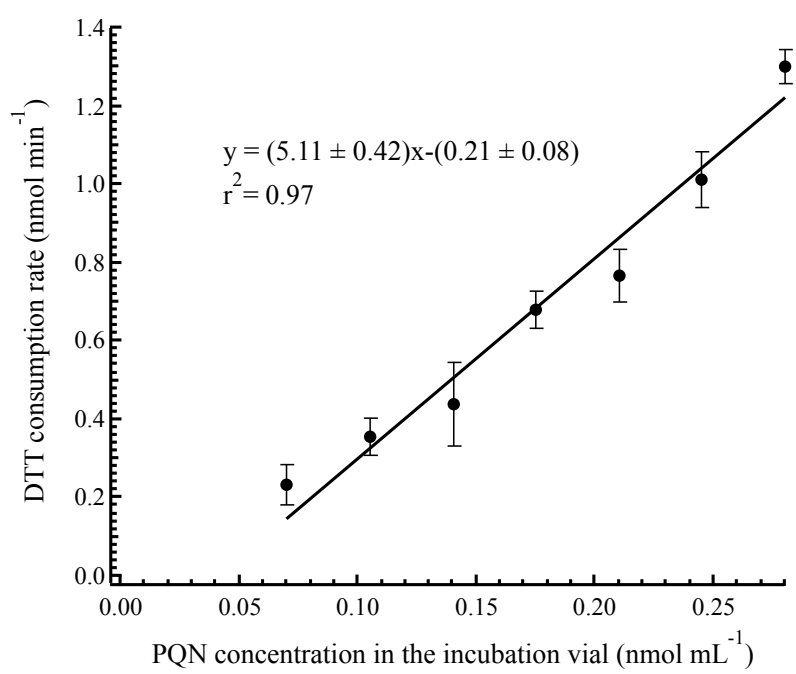

Figure 3. Blank-corrected DTT consumption rate as a function of PQN showing linearity between PQN concentrations and DTT consumption rate for the total analytical system (for PQN levels shown in the range above). Error bar represents the standard deviation of three independent DTT measurements on each concentration.

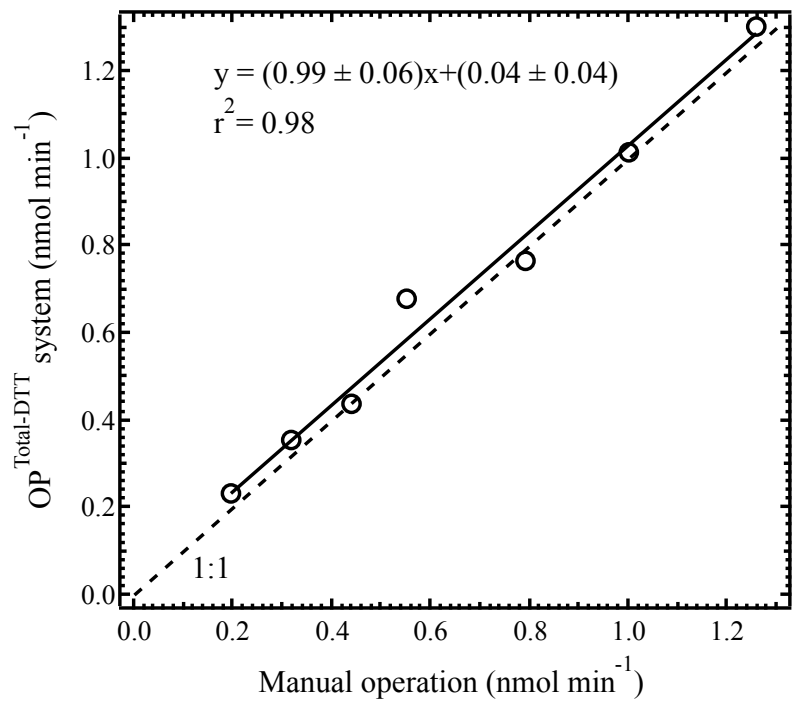

Figure 4. DTT consumption rate (blank-corrected) comparison of the automated system for measuring OP ${ }^{\text {Total-DTT }}$ (shown in Fig. 2) to a manual analysis using PQN (9,10-phenanthraquinone). Slope ( \pm 1 standard deviation) and intercept ( \pm 1 standard deviation) are based on orthogonal regression.

is used to assess the precision of each method. The results are summarized in Table 1. CV ranged from 3 to $6 \%$ for method 1 , which may result from the combined uncertainties of the two respective steps (i.e., extraction and analysis). The range of $\mathrm{CV}$ for method 2 was from 5 to $12 \%$. The root of this variability may arise from the insoluble material remaining in the reaction suspension that was difficult to reproduce from run to run. In contrast, lower CV $(1 \% \sim 5 \%)$ was ob- 

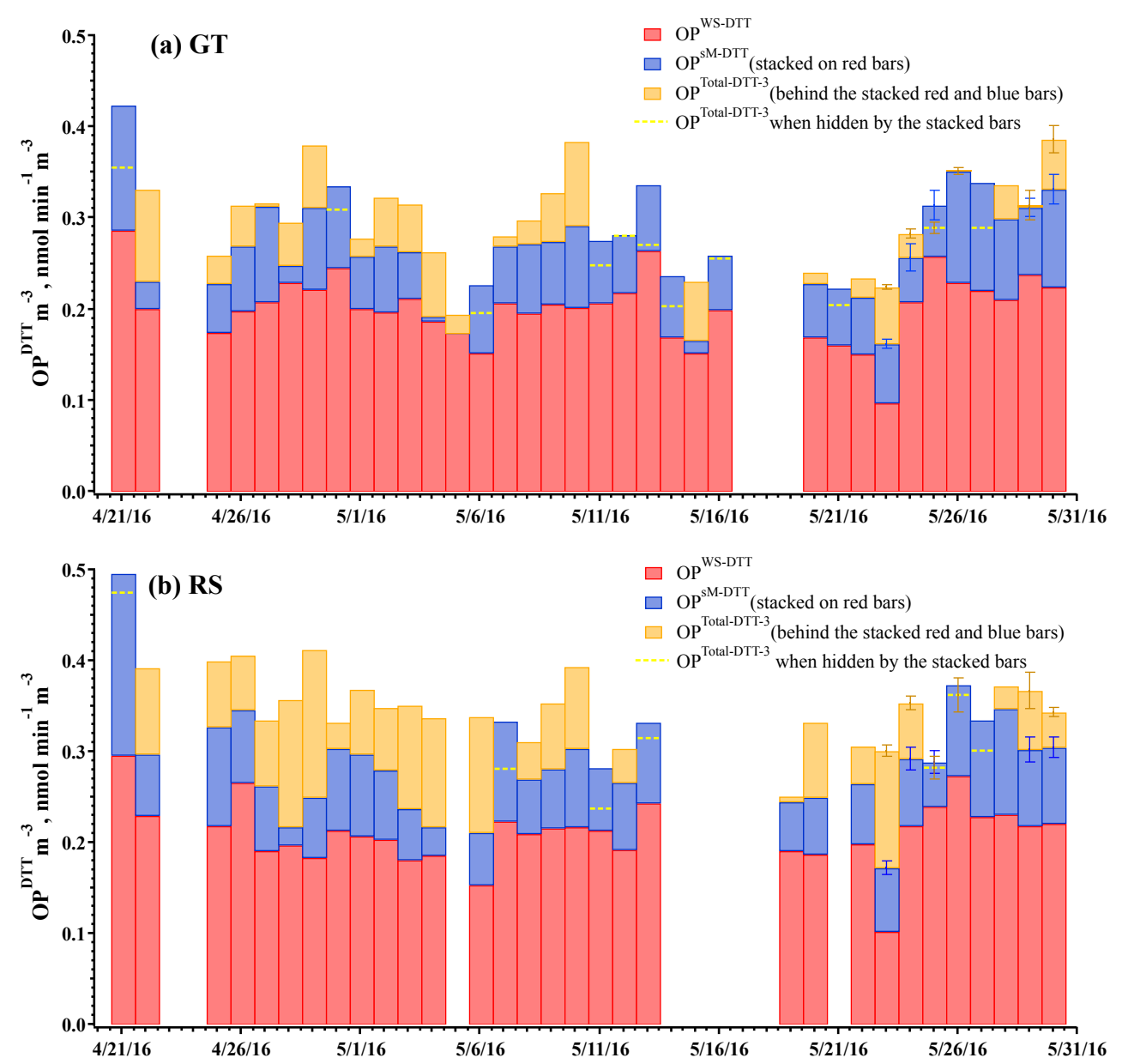

Figure 5. Comparison of OPDTT $\mathrm{m}^{-3}$ between extraction methods 1 and 3 at (a) GT $(N=35)$ and (b) RS $(N=31)$. Error bars denote 1 standard deviation in OPDTT $\mathrm{m}^{-3}$ from repeated measurements and are propagated in calculating OPTotal-DTT-1.

Table 1. Coefficient of variation $(\mathrm{CV})$ of OPTotal-DTT for three extraction methods.

\begin{tabular}{llll}
\hline & Method 1 & Method 2 & Method 3 \\
\hline Coefficient of variation & $3-6 \%$ & $5-12 \%$ & $1-5 \%$ \\
(CV) from triplicate & $N=10$ & $N=7$ & $N=12$ \\
\hline
\end{tabular}

$N$ is the number of HiVol filters tested.

served for method 3, possibly because it involved the fewest steps in the filter extraction.

\subsection{Comparison of methods for measuring total oxidative potential (OP ${ }^{\text {Total-DTT }}$ )}

\subsubsection{Comparison of oxidative potential}

In the following, $\mathrm{OP}^{\mathrm{DTT}}$ per cubic meter determined by the three methods for simultaneously collected HiVol quartz filters at the GT and RS sites are compared. Since no stan- dard method is available for assessing the ability to measure $\mathrm{OP}^{\mathrm{DTT}}$ per cubic meter, we simply compare the various methods and assume that the highest measurement represents the most comprehensive analytical method for measuring total oxidative potential. No HiVol conversion factors were applied to the OP data as the three methods were all performed on filters collected using the same HiVol sampler at each site.

Figure 5 shows the $\mathrm{OP}^{\mathrm{DTT}}$ per cubic meter comparison between methods 1 and 3 at both GT and RS sites. In general, the response of the DTT assay of method 3 was significantly higher than that of method 1 at the $95 \%$ confidence level (paired $t$ test: $p=0.028$ at GT, $N=35 ; p<$ 0.001 at $\mathrm{RS}, N=31$ ). The results are expected since in method 1 both the water and methanol liquid extracts are filtered, potentially removing species that could have been DTT-active but remained attached to solid particles. A few observations where $\mathrm{OP}^{\text {Total-DTT-3 }}$ is less than OP ${ }^{\text {Total-DTT-1 }}$ are likely due to propagation of errors for the summation method (method 1) combined with variability in the extraction process for each method. The mean OP ${ }^{\text {Total-DTT-1 }}$ 

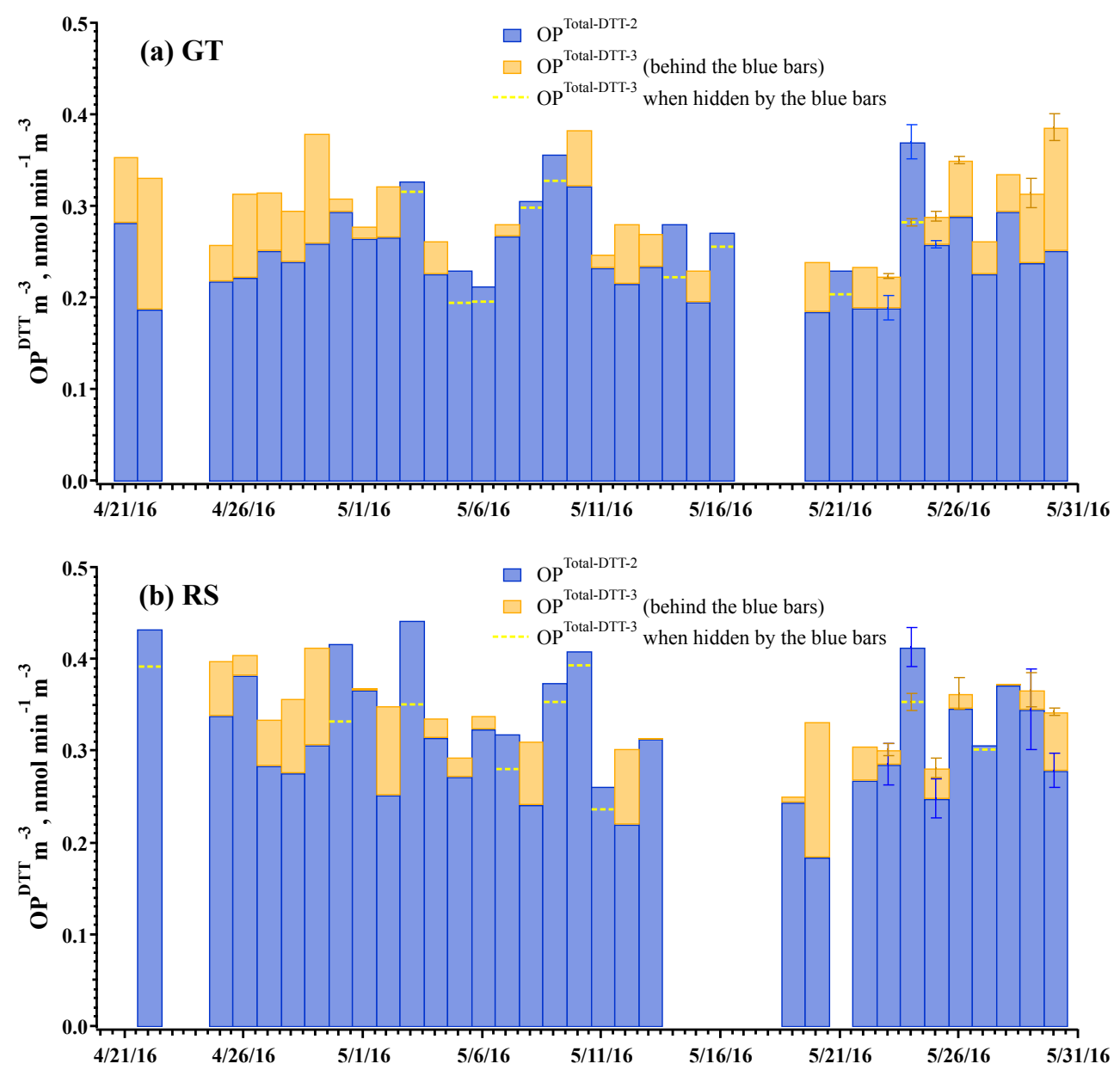

Figure 6. Comparison of OPDTT $\mathrm{m}^{-3}$ between methods 2 and 3 at (a) GT $(N=35)$ and $(\mathbf{b})$ RS $(N=31)$. Error bars denote 1 standard deviation in $\mathrm{OP}^{\mathrm{DTT}} \mathrm{m}^{-3}$ from repeated measurements.

to-OP ${ }^{\text {Total-DTT-3 }}$ ratio at GT was close to 1 (ratio $\left.=0.95\right)$ and also higher than that at RS (ratio $=0.85)$. The lower $\mathrm{OP}^{\text {Total-DTT-1 }}$ may be due to liquid filtration after water extraction. The ratios of OP ${ }^{\text {sM-DTT }}$ to OPWS-DTT are $0.34 \pm 0.14$ $(N=35)$ at $\mathrm{GT}$ and $0.37 \pm 0.12(N=31)$ at $\mathrm{RS}$, which are consistent with the ratios from SCAPE data $(0.27 \pm 0.08$, $N=198$; unpublished data) and fall into the typical range of ambient samples. The water-insoluble OP determined by the difference in OP ${ }^{\text {Total-DTT-3 }}$ (which includes solid particles) and the ratio of OP ${ }^{\text {WS-DTT }}$ (OP ${ }^{\text {WI-DTT-3 }}=\mathrm{OP}^{\text {Total-DTT-3 }}-$ $\left.\mathrm{OP}^{\mathrm{WS}-\mathrm{DTT}}\right)$ to OP ${ }^{\mathrm{WS}-\mathrm{DTT}}$, by contrast, is $0.45 \pm 0.25$ at GT $(N=35)$ and $0.67 \pm 0.35$ at $\mathrm{RS}(N=31)$. There was very little correlation between the OP ${ }^{\text {WI-DTT-3 }}$ and OPWS-DTT, with Pearson correlations of $r=-0.23$ and -0.51 at GT and RS sites, respectively (see Table S1), which further indicates the importance of water-insoluble compounds to a total OP measurement. Additionally, OP ${ }^{\mathrm{WI}-\mathrm{DTT}-3}$ was weakly correlated with OP ${ }^{\text {SM-DTT }}$ (Pearson correlation: $r=0.31$ at GT, $r=0.04$ at RS). Based on these data, it is clear that there were species associated with water-insoluble $\mathrm{OP}^{\mathrm{DTT}}$ not ex- tracted by methanol and that remain attached to solid particles. This analysis shows that filtering the liquid extract, even if methanol solvent is used, will result in a substantial underestimation of OP ${ }^{\text {Total-DTT }}$. Therefore, in terms of the OP response, method 3 is preferred to method 1 . Furthermore, the comparison between these two methods can provide insights into the water-insoluble components that contribute to PM OP.

Figure 6 shows the comparison of OP ${ }^{\mathrm{DTT}}$ per cubic meter between methods 2 and 3 at both GT and RS sites. At the GT site, method 3 generally yielded higher OP responses than method 2, with a mean OP ${ }^{\text {Total-DTT-2 }}$-to-OP ${ }^{\text {Total-DTT-3 }}$ ratio of $0.90(p<0.001$ for a paired $t$ test, $N=35)$. For the RS site, however, method 2 was able to produce comparable ( $p=0.060$ for a paired $t$ test, $N=31$ ) or even higher OP responses, at times, than method 3 with a OP Total-DTT-2 $^{\text {to- }}$ OP $^{\text {Total-DTT-3 }}$ ratio of 0.94 , which may imply that method 2, in some cases, might be more efficient in extracting DTTactive species from the unique RS sources such as vehicular emissions. 


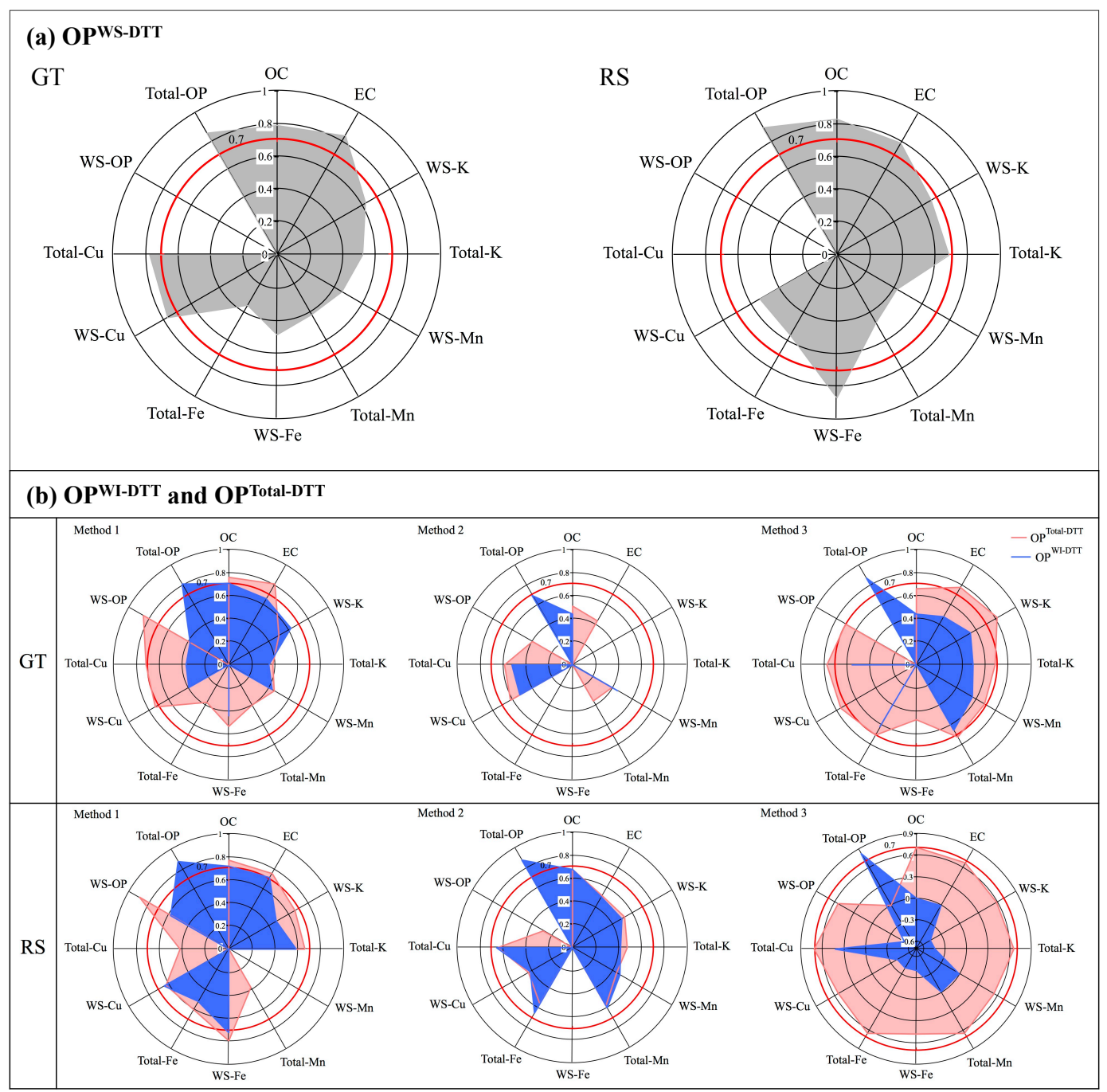

Figure 7. Polar plots comparing Pearson correlation coefficients $(r)$ between various forms of $\mathrm{OP}^{\mathrm{DTT}} \mathrm{m}^{-3}\left(\mathbf{a ~ O P}^{\mathrm{WS}-\mathrm{DTT}}\right.$, $\mathbf{b}$ OP WI-DTT and $\mathrm{OP}^{\text {Total-DTT}}$; red: OP ${ }^{\text {Total-DTT}}$; blue: OPWI-DTT $\left(\mathrm{OP}^{\mathrm{WI}-\mathrm{DTT}}=\mathrm{OP}^{\text {Total-DTT }}-\mathrm{OP}^{\mathrm{WS}-\mathrm{DTT}}\right.$ for methods 2 and 3$\left.)\right)$ and PM chemical components at GT $(N=34)$ and $\mathrm{RS}(N=29)$ sites. Correlations not statistically significant ( $p$ value $>0.05)$ are not shown on the plots but can be found in Table S2. The red line indicates $r=0.7$. Note: the scales for method $3 \mathrm{RS}$ are different from those for the other methods.

From the perspective of OP response, method 3 generally produced the highest signals compared to the other two methods, in both the urban (GT) and near-road (RS) sites.

\subsubsection{Association between $\mathrm{OP}^{\mathrm{DTT}}$ and PM composition}

A correlation analysis was performed between measured $\mathrm{PM}_{2.5}$ chemical constituents and $\mathrm{OP}^{\mathrm{DTT}}$ determined by the three methods. Figure 7 shows the correlation results (detailed values are provided in Table S2). It is seen that OP ${ }^{\text {Total-DTT-3 }}$ is better correlated with the measured

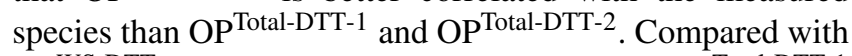
OPWS-DTT , the stronger correlations between OPTotal-DTT-1 and PM species suggest that OP ${ }^{\text {Total-DTT-1 }}$ captures more chemical components contributing to DTT than OPWS-DTT
In contrast, $\mathrm{OP}^{\text {Total-DTT-2 }}$ is correlated with the fewest number of measured PM species.

By subtracting OPWS-DTT from OP ${ }^{\text {Total-DTT }}$, OP ${ }^{\text {WI-DTT }}$ is determined for the three methods. In general, the correlations between OP ${ }^{\mathrm{WI}-\mathrm{DTT}}$ and PM species are mediocre for all three methods, with a slightly better performance of method 1 . The water-insoluble $\mathrm{OP}^{\mathrm{DTT}}$ determined by method 1, i.e., $\mathrm{OP}^{\mathrm{sM}-\mathrm{DTT}}$, has good correlation with OC at GT and OC, EC, and water-soluble Fe at RS. Verma et al. (2012) also showed good correlations between $\mathrm{OP}^{\mathrm{DTT}}$ of filtered methanol extracts and $\mathrm{OC}$ and EC, and attributed this association to water-insoluble organic carbon species (WIOC) that dissolve in methanol. Thus, OP ${ }^{\text {sM-DTT }}$ in method 1 is likely attributed to some fraction of the WIOC. OP ${ }^{\text {WI-DTT }} \mathrm{ob}$ tained in method 1 is determined from the direct measure 
of OP $^{\text {sM-DTT }}$, whereas OP ${ }^{\text {WI-DTT }}$ is determined by the difference for methods 2 and 3, which leads to larger uncertainty and more scatter associated with these data.

The overall assessment of the three methods is summarized in Table 2. By comparison, it is found that method 3 has better precision, more comprehensive response (i.e., generally highest $\mathrm{OP}^{\text {Total-DTT }}$ ), stronger correlations with PM components, and easiest filter preparation (extraction) process, all of which provide an efficient way for OP ${ }^{\text {Total-DTT }}$ determination. The other two methods have some value owing to their insights into the attributes of water-insoluble OP contributors. In a subsequent study, discussed next, only method 3 was utilized to measure $\mathrm{OP}^{\text {Total-DTT }}$ of PM for Teflon filters.

\subsection{OP ${ }^{\text {WS-DTT }}$ and OP ${ }^{\text {Total-DTT }}$ measurements on quartz versus Teflon filters and their spatial distributions}

The time series of volume-normalized water-soluble and total $\mathrm{OP}^{\mathrm{DTT}}$ via method 3 are shown in Fig. 8 for two different sample time periods using HiVol samplers with quartz filters (21 April-30 May 2016; HiVol conversion factors of 1.00 and 1.10 were applied to GT OP ${ }^{\text {WS-DTT }}$ and OP ${ }^{\text {Total-DTT }}$ data, respectively) and PCMs with Teflon filters (26 July-21 August 2016). A summary of the average OP data is given in Table S3. The ANOVA results (Table S4) indicate negligible difference between types of filter (i.e., quartz versus Teflon) on $\mathrm{OP}^{\mathrm{DTT}}$ measurements.

Figure 8 shows that, as expected, OP ${ }^{\text {Total-DTT }}$ is always higher than $\mathrm{OP}^{\mathrm{WS}-\mathrm{DTT}}$. The ratios of OPWS-DTT to OP $^{\text {Total-DTT }}$ were on average $65 \pm 10 \%$ (insoluble accounts for $35 \pm 10 \%$ ) and $65 \pm 14 \%$ at GT, compared to $62 \pm 12 \%$ and $58 \pm 10 \%$ at RS, for quartz and Teflon PM samples, respectively. Thus, OP Total-DTT of $\mathrm{PM}_{2.5}$ contained on average $35-42 \%$ insoluble species. The correlation coefficients between OP ${ }^{\text {WI-DTT }}$ and OP ${ }^{\text {Total-DTT }}$ were 0.87 and 0.84 for quartz filters at GT and RS, respectively (Table S1), which reflects the contribution of insoluble species to total OP as well.

Spatial distributions in $\mathrm{OP}^{\mathrm{DTT}}$ can also be investigated. As discussed above, the water-soluble fraction of total $\mathrm{OP}$ (OP ${ }^{\text {WS-DTT }}$-to-OP ${ }^{\text {Total-DTT }}$ ratio) was fairly similar at the two sites, which means that the insoluble fraction was not vastly different between the two sites. Figure 9 shows a summary of daily concentration ratios between the sites. EC, a marker for incomplete combustion and thus associated with vehicle emissions, was much higher at the RS site; the ratio of RS to GT was 3.2 on average. OC was only slightly elevated, as expected, since OC is largely secondary in Atlanta (Xu et al., 2015) and so more spatially uniform (i.e., primary OC is a small fraction of total OC, even at RS). Both OP ${ }^{\text {WS-DTT }}$ and OP ${ }^{\text {Total-DTT }}$ were spatially uniform with daily RS-to-GT OP ratios close to 1 . COD was also calculated to further assess the spatial variability of OP (Table S6). The low COD values $(\mathrm{COD}<0.08$ for the quartz filters and

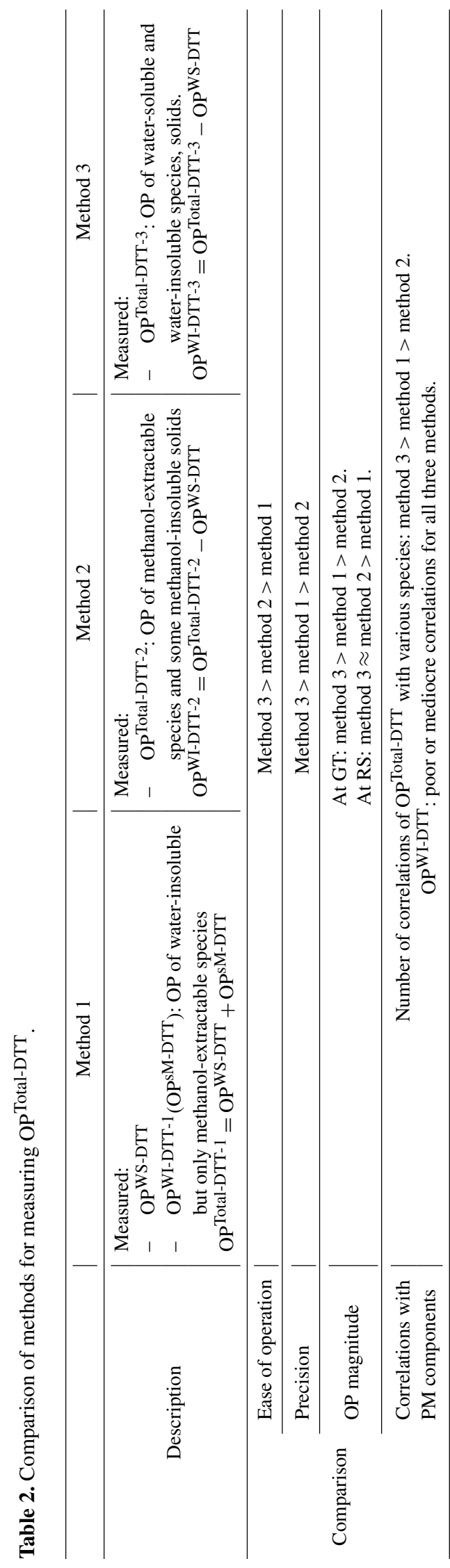

Atmos. Meas. Tech., 10, 2821-2835, 2017 

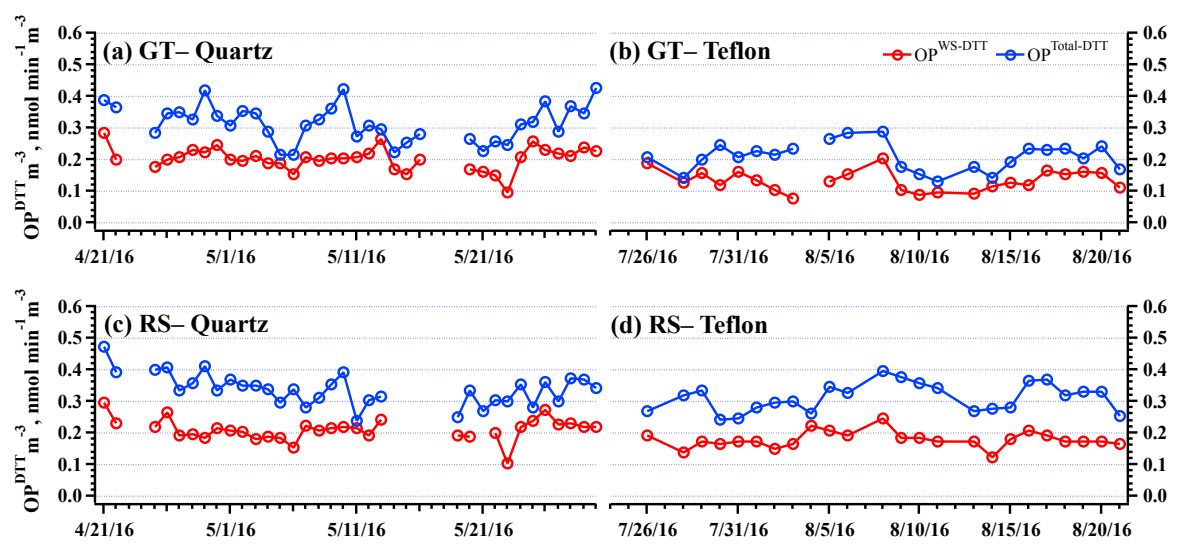

Figure 8. Volume-normalized OPDT of ambient $\mathrm{PM}_{2.5}$ particles collected on quartz and Teflon filters at GT and RS sites for two different sampling time periods. Red lines indicate volume-normalized OPWS-DTT, and blue lines denote volume-normalized OP ${ }^{\text {Total-DTT }}$.

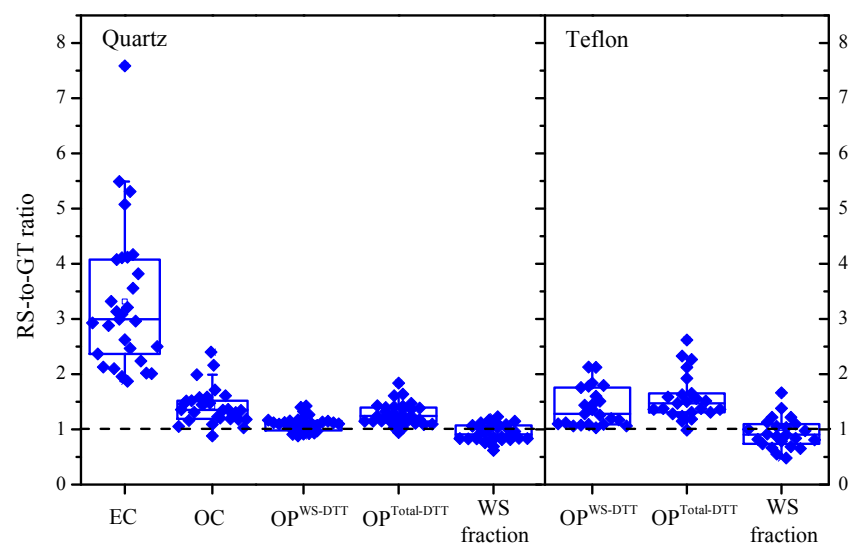

Figure 9. Comparison of simultaneous measurements at GT and RS sites based on daily RS-to-GT concentration ratios. The bottom and top of the box are the first (Q1) and third quartiles (Q3), and the band inside the box is the median. The lowest and highest ends of whisker are (Q1-1.5IQR) and (Q3 + 1.5IQR), where the interquartile range $(\mathrm{IQR})=\mathrm{Q} 3-\mathrm{Q} 1$.

$<0.23$ for the Teflon filters) between the RS and GT site indicate spatial homogeneity of OP during the sampling periods. This was found for both quartz and Teflon filters. The homogenous distributions of OP are very similar to that of $\mathrm{OC}(\mathrm{COD}=0.18)$ and in contrast to $\mathrm{EC}(\mathrm{COD}=0.52)$. Note that both OP ${ }^{\text {WS-DTT }}$ and $\mathrm{OP}^{\text {Total-DTT }}$ were slightly higher at the RS site, possibly indicating a linkage to RS emissions. Uniformity of OP ${ }^{\text {WS-DTT }}$ is consistent with the results shown in the study of Fang et al. (2015), but similar uniformity in OP ${ }^{\text {Total-DTT }}$ may seem somewhat unexpected since waterinsoluble aerosol components are often associated with primary species. These data show the importance of secondary atmospheric processes to OPWI-DTT. The results are consistent with studies that have found water-insoluble DTTactive constituents could be secondary quinones from oxi- dized polycyclic aromatic hydrocarbons that remain bound to the surface of soot particles associated with traffic emissions (Antinolo et al., 2015; Li et al., 2013; Shiraiwa et al., 2012). This means that, although roadway emissions are a source for components that contribute to OP, some form of processing is needed to convert the roadway emissions to species with measurable oxidative potential for both OP ${ }^{\text {Total-DTT }}$ and OPWS-DTT . Size distributions of OPWI-DTT (Fang et al., 2017) suggest that $\mathrm{OP}^{\mathrm{WI}-\mathrm{DTT}}$ is composed of different types of insoluble species; that OP from oxidized aromatic species (e.g., quinones) may be mainly associated with smaller-sized insoluble soot particles; and that, at the large end of the $\mathrm{PM}_{2.5}$ size range, transition metal ions (i.e., water-soluble $\mathrm{Cu}$ ) associated with road and brake dust may be the main source.

\section{Summary}

An automated analytical system was developed for quantifying total aerosol oxidative potential with the DTT assay $\left(\mathrm{OP}^{\text {Total-DTT}}\right)$ from filter sample extracts. The method is based on modifying an automated analytical system developed by Fang et al. (2015) for measuring water-soluble oxidative potential (OP $\left.{ }^{\mathrm{WS}-\mathrm{DTT}}\right)$. Three methods for including the contribution of water-insoluble components to oxidative potential of PM $\left(\mathrm{OP}^{\mathrm{WI}-\mathrm{DTT}}\right)$ for a measurement of OPTotal-DTT were tested: (1) extracting filter punches in deionized water, filtering the extract, and measuring OPWS-DTT; followed by methanol extraction on the same filter, filtering the extract, and removing most methanol by evaporation; and then reconstituting in water and summing with OPWS-DTT to obtain OP $^{\text {Total-DTT }}$; (2) extracting filter punches in methanol, reconstituting the unfiltered methanol extracts with DI after evaporation of methanol, and performing the DTT assay on the DI-reconstituted suspension; and (3) extracting filter punches in a vial with DI and then performing the DTT assay in the vial containing the fil- 
ter. Method 3 generally yielded higher DTT responses with higher precision (coefficient of variation of $1 \sim 5 \%$ ) and was highly correlated with more aerosol species, including OC, $\mathrm{EC}$, and various water-soluble and total elements. Because this method requires no use of organic solvents that must be mostly eliminated prior to DTT analysis, it is the easiest to automate. The automated system for measuring OPWS-DTT (Fang et al., 2015) was modified to follow method 3, and the system performance was tested.

An ambient study was conducted to contrast measures of OP ${ }^{\text {Total-DTT }}$ and OPWS-DTT for PM $_{2.5}$ collected at a roadside (RS) site (highway with restricted heavy-duty diesel access) and a site more representative of overall average urban Atlanta air quality (GT). Simultaneous daily filter samples were collected during two separate 1-month periods, and comparisons were made using quartz and Teflon filters. At the representative urban site (GT), the ratio of OP ${ }^{\text {WS-DTT }}$ to $\mathrm{OP}^{\text {Total-DTT }}$ was $65 \%$ for both types of filters. At the roadside site (RS) the ratio was only slightly lower: $62 \%$ for quartz filters and $58 \%$ for Teflon filters. OP ${ }^{\text {WS-DTT }}$ and OPTotal-DTT were moderately correlated with Pearson product correlation coefficients between 0.56 (roadside) and 0.71 (urban). Simultaneous measures of OP ${ }^{\text {WS-DTT }}$ and $\mathrm{OP}^{\text {Total-DTT }}$ at the GT and RS site showed only slightly higher levels of both at the RS site, indicating both OP ${ }^{\text {WS-DTT }}$ and OP ${ }^{\text {Total-DTT }}$ were spatially homogeneous. The results are consistent with roadway emissions as sources of OP but indicate that $\mathrm{PM}_{2.5} \mathrm{OP}$ was largely secondary for both soluble and insoluble aerosol components contributing to OP.

Data availability. The data supporting the findings of this study are available from the authors upon reasonable request.

The Supplement related to this article is available online at https://doi.org/10.5194/amt-10-2821-2017-supplement.

Competing interests. The authors declare that they have no conflict of interest.

Acknowledgements. We would like to thank Emily Saad for ICPMS analysis. This work was funded through a research agreement with the Health Effects Institute (no. 4942-RFA13-1/14-3) and EPA Science to Achieve Results (STAR) grant R834799 that supported the Southeastern Center for Air Pollution \& Epidemiology (SCAPE). The contents are solely the responsibility of the grantee and do not necessarily represent the official views of the sponsors. Further, US EPA does not endorse the purchase of any commercial products or services mentioned in the publication.

Edited by: Pierre Herckes

Reviewed by: four anonymous referees

\section{References}

Akhtar, U. S., McWhinney, R. D., Rastogi, N., Abbatt, J. P. D., Evans, G. J., and Scott, J. A.: Cytotoxic and proinflammatory effects of ambient and source-related particulate matter (PM) in relation to the production of reactive oxygen species (ROS) and cytokine adsorption by particles, Inhal. Toxicol., 22, 37-47, https://doi.org/10.3109/08958378.2010.518377, 2010.

Antinolo, M., Willis, M. D., Zhou, S. M., and Abbatt, J. P. D.: Connecting the oxidation of soot to its redox cycling abilities, Nature Communications, 6, 6812, https://doi.org/10.1038/ncomms7812, 2015.

Artaxo, P., Gerab, F., Yamasoe, M. A., and Martins, J. V.: Fine mode aerosol composition at three long-term atmospheric monitoring sites in the Amazon Basin, J. Geophys. Res., 99, 22857-22868, https://doi.org/10.1029/94jd01023, 1994.

Atkinson, R. W., Anderson, H. R., Sunyer, J., Ayres, J., Baccini, M., Vonk, J. M., Boumghar, A., Forastiere, F., Forsberg, B., Touloumi, G., Schwartz, J., and Katsouyanni, K.: Acute effects of particulate air pollution on respiratory admissions - Results from APHEA 2 project, Am. J. Resp. Crit. Care, 164, 18601866, https://doi.org/10.1164/ajrccm.164.10.2010138, 2001.

Atkinson, R. W., Samoli, E., Analitis, A., Fuller, G. W., Green, D. C., Anderson, H. R., Purdie, E., Durister, C., Aitlhadj, L., Kelly, F. J., and Mudway, I. S.: Short-term associations between particle oxidative potential and daily mortality and hospital admissions in London, Int. J. Hyg. Envir. Heal., 219, 566-572, https://doi.org/10.1016/j.ijheh.2016.06.004, 2016.

Ayres, J. G., Borm, P., Cassee, F. R., Castranova, V., Donaldson, K., Ghio, A., Harrison, R. M., Hider, R., Kelly, F., Kooter, I. M., Marano, F., Maynard, R. L., Mudway, I., Nel, A., Sioutas, C., Smith, S., Baeza-Squiban, A., Cho, A., Duggan, S., and Froines, J.: Evaluating the toxicity of airborne particulate matter and nanoparticles by measuring oxidative stress potential a workshop report and consensus statement, Inhal. Toxicol., 20, 75-99, https://doi.org/10.1080/08958370701665517, 2008.

Bates, J. T., Weber, R. J., Abrams, J., Verma, V., Fang, T., Klein, M., Strickland, M. J., Sarnat, S. E., Chang, H. H., Mulholland, J. A., Tolbert, P. E., and Russell, A. G.: Reactive Oxygen Species Generation Linked to Sources of Atmospheric Particulate Matter and Cardiorespiratory Effects, Environ. Sci. Technol., 49, 13605-13612, https://doi.org/10.1021/acs.est.5b02967, 2015.

Canova, C., Minelli, C., Dunster, C., Kelly, F., Shah, P. L., Caneja, C., Tumilty, M. K., and Burney, P.: $\mathrm{PM}_{10}$ Oxidative Properties and Asthma and COPD, Epidemiology, 25, 467-468, https://doi.org/10.1097/Ede.0000000000000084, 2014.

Charrier, J. G. and Anastasio, C.: On dithiothreitol (DTT) as a measure of oxidative potential for ambient particles: evidence for the importance of soluble transition metals, Atmos. Chem. Phys., 12, 9321-9333, https://doi.org/10.5194/acp-12-9321-2012, 2012.

Charrier, J. G., McFall, A. S., Vu, K. K. T., Baroi, J., Olea, C., Hasson, A., and Anastasio, C.: A bias in the "mass-normalized" DTT response - An effect of non-linear concentration-response curves for copper and manganese, Atmos. Environ., 144, 325334, https://doi.org/10.1016/j.atmosenv.2016.08.071, 2016.

Cho, A. K., Sioutas, C., Miguel, A. H., Kumagai, Y., Schmitz, D. A., Singh, M., Eiguren-Fernandez, A., and Froines, J. R.: Redox activity of airborne particulate matter at different sites in the Los Angeles Basin, Environ. Res., 99, 40-47, https://doi.org/10.1016/j.envres.2005.01.003, 2005. 
Chow, J. C., Watson, J. G., Pritchett, L. C., Pierson, W. R., Frazier, C. A., and Purcell, R. G.: The Dri Thermal Optical Reflectance Carbon Analysis System - Description, Evaluation and Applications in United-States Air-Quality Studies, Atmos. Environ. A-Gen., 27, 1185-1201, https://doi.org/10.1016/09601686(93)90245-T, 1993.

Daher, N., Ning, Z., Cho, A. K., Shafer, M., Schauer, J. J., and Sioutas, C.: Comparison of the Chemical and Oxidative Characteristics of Particulate Matter (PM) Collected by Different Methods: Filters, Impactors, and BioSamplers, Aerosol Sci. Tech., 45, 1294-1304, https://doi.org/10.1080/02786826.2011.590554, 2011.

Delfino, R. J., Sioutas, C., and Malik, S.: Potential role of ultrafine particles in associations between airborne particle mass and cardiovascular health, Environ. Health Persp., 113, 934-946, https://doi.org/10.1289/ehp.7938, 2005.

Delfino, R. J., Staimer, N., and Vaziri, N. D.: Air pollution and circulating biomarkers of oxidative stress, Air Quality, Atmosphere \& Health, 4, 37-52, https://doi.org/10.1007/s11869-010-0095-2, 2011.

Delfino, R. J., Staimer, N., Tjoa, T., Gillen, D. L., Schauer, J. J., and Shafer, M. M.: Airway inflammation and oxidative potential of air pollutant particles in a pediatric asthma panel, J. Expo. Sci. Env. Epid., 23, 466-473, https://doi.org/10.1038/jes.2013.25, 2013.

Donaldson, K., Stone, V., Seaton, A., and MacNee, W.: Ambient particle inhalation and the cardiovascular system: Potential mechanisms, Environ. Health Persp., 109, 523-527, https://doi.org/10.2307/3454663, 2001.

Fang, T., Verma, V., Guo, H., King, L. E., Edgerton, E. S., and Weber, R. J.: A semi-automated system for quantifying the oxidative potential of ambient particles in aqueous extracts using the dithiothreitol (DTT) assay: results from the Southeastern Center for Air Pollution and Epidemiology (SCAPE), Atmos. Meas. Tech., 8, 471-482, https://doi.org/10.5194/amt-8471-2015, 2015.

Fang, T., Verma, V., Bates, J. T., Abrams, J., Klein, M., Strickland, M. J., Sarnat, S. E., Chang, H. H., Mulholland, J. A., Tolbert, P. E., Russell, A. G., and Weber, R. J.: Oxidative potential of ambient water-soluble $\mathrm{PM}_{2.5}$ in the southeastern United States: contrasts in sources and health associations between ascorbic acid (AA) and dithiothreitol (DTT) assays, Atmos. Chem. Phys., 16, 3865-3879, https://doi.org/10.5194/acp-16-3865-2016, 2016.

Fang, T., Zeng, L., Gao, D., Verma, V., Stefaniak, A. B., and Weber, R. J.: Ambient size distributions and lung deposition of aerosol oxidative potential: a contrast between soluble and insoluble particles, Environ. Sci. Technol., 51, 6802-6811, https://doi.org/10.1021/acs.est.7b01536, 2017.

GDOT - Georgia Department of Transportation Traffic: Data, http://www.dot.ga.gov/DriveSmart/Data/Documents/ ATRTrafficDataReports/2013_TruckPercentagesByLocation.pdf (last access: 2 August 2017), 2013.

GDOT - Georgia Department of Transportation: Traffic Data, http://trafficserver.transmetric.com/gdot-prod/tcdb.jsp?siteid= 1215482 (last access: 2 August 2017), 2015.

Janssen, N. A. H., Strak, M., Yang, A., Hellack, B., Kelly, F. J., Kuhlbusch, T. A. J., Harrison, R. M., Brunekreef, B., Cassee, F. R., Steenhof, M., and Hoek, G.: Associations between three specific a-cellular measures of the oxidative potential of partic- ulate matter and markers of acute airway and nasal inflammation in healthy volunteers, Occup. Environ. Med., 72, 49-56, https://doi.org/10.1136/oemed-2014-102303, 2015.

King, L. E. and Weber, R. J.: Development and testing of an online method to measure ambient fine particulate reactive oxygen species (ROS) based on the 2',7'dichlorofluorescin (DCFH) assay, Atmos. Meas. Tech., 6, 16471658, https://doi.org/10.5194/amt-6-1647-2013, 2013.

Kumagai, Y., Koide, S., Taguchi, K., Endo, A., Nakai, Y., Yoshikawa, T., and Shimojo, N.: Oxidation of proximal protein sulfhydryls by phenanthraquinone, a component of diesel exhaust particles, Chem. Res. Toxicol., 15, 483-489, https://doi.org/10.1021/tx0100993, 2002.

Lakey, P. S. J., Berkemeier, T., Tong, H. J., Arangio, A. M., Lucas, K., Pöschl, U., and Shiraiwa, M.: Chemical exposure-response relationship between air pollutants and reactive oxygen species in the human respiratory tract, Scientific Reports, 6, 32916, https://doi.org/10.1038/srep32916, 2016.

Li, N., Hao, M. Q., Phalen, R. F., Hinds, W. C., and Nel, A. E.: Particulate air pollutants and asthma - A paradigm for the role of oxidative stress in PM-induced adverse health effects, Clin. Immunol., 109, 250-265, https://doi.org/10.1016/j.clim.2003.08.006, 2003a.

Li, N., Sioutas, C., Cho, A., Schmitz, D., Misra, C., Sempf, J., Wang, M. Y., Oberley, T., Froines, J., and Nel, A.: Ultrafine particulate pollutants induce oxidative stress and mitochondrial damage, Environ. Health Persp., 111, 455-460, https://doi.org/10.1289/ehp.6000, 2003b.

Li, Q., Shang, J., and Zhu, T.: Physicochemical characteristics and toxic effects of ozone-oxidized black carbon particles, Atmos. Environ., 81, 68-75, https://doi.org/10.1016/j.atmosenv.2013.08.043, 2013.

Lim, S. S., Vos, T., and Flaxman, A. D.: A comparative risk assessment of burden of disease and injury attributable to 67 risk factors and risk factor clusters in 21 regions, 1990-2010: a systematic analysis for the Global Burden of Disease Study 2010, Lancet, 380, 2224-2260, https://doi.org/10.1016/S0140-6736(12)617668, 2012.

Lin, P. and Yu, J. Z.: Generation of Reactive Oxygen Species Mediated by Humic-like Substances in Atmospheric Aerosols, Environ Sci Technol, 45, 10362-10368, https://doi.org/10.1021/es2028229, 2011.

McWhinney, R. D., Badali, K., Liggio, J., Li, S. M., and Abbatt, J. P. D.: Filterable Redox Cycling Activity: A Comparison between Diesel Exhaust Particles and Secondary Organic Aerosol Constituents, Environ. Sci. Technol., 47, 3362-3369, https://doi.org/10.1021/es304676x, 2013.

Miljevic, B., Hedayat, F., Stevanovic, S., Fairfull-Smith, K. E., Bottle, S. E., and Ristovski, Z. D.: To Sonicate or Not to Sonicate PM Filters: Reactive Oxygen Species Generation Upon Ultrasonic Irradiation, Aerosol Sci. Tech., 48, 1276-1284, https://doi.org/10.1080/02786826.2014.981330, 2014.

Mudway, I. S., Stenfors, N., Duggan, S. T., Roxborough, H., Zielinski, H., Marklund, S. L., Blomberg, A., Frew, A. J., Sandstrom, T., and Kelly, F. J.: An in vitro and in vivo investigation of the effects of diesel exhaust on human airway lining fluid antioxidants, Arch. Biochem. Biophys., 423, 200-212, https://doi.org/10.1016/j.abb.2003.12.018, 2004. 
Nel, A.: Air pollution-related illness: effects of particles, Science, 308, 804-806, https://doi.org/10.1126/science.1108752, 2005.

Pinto, J. P., Lefohn, A. S., and Shadwick, D. S.: Spatial variability of $\mathrm{PM}_{2.5}$ in urban areas in the United States, J. Air Waste Manage., 54, 440-449, https://doi.org/10.1080/10473289.2004.10470919, 2004.

Pope, C. A.: Particulate Air-Pollution and Human Health - Assessment of the Epidemiology, Inhal. Toxicol., 7, 749-752, https://doi.org/10.3109/08958379509014478, 1995.

Pope, C. A. and Dockery, D. W.: Health effects of fine particulate air pollution: Lines that connect, J. Air Waste Manage., 56, 709742, https://doi.org/10.1080/10473289.2006.10464485, 2006.

Schoonen, M. A. A., Cohn, C. A., Roemer, E., Laffers, R., Simon, S. R., and O'Riordan, T.: Mineral-induced formation of reactive oxygen species, Rev. Mineral. Geochem., 64, 179-221, https://doi.org/10.2138/rmg.2006.64.7, 2006.

Shi, T. M., Schins, R. P. F., Knaapen, A. M., Kuhlbusch, T., Pitz, M., Heinrich, J., and Borm, P. J. A.: Hydroxyl radical generation by electron paramagnetic resonance as a new method to monitor ambient particulate matter composition, J. Environ. Monitor., 5, 550-556, https://doi.org/10.1039/b303928p, 2003.

Shiraiwa, M., Selzle, K., and Pöschl, U.: Hazardous components and health effects of atmospheric aerosol particles: reactive oxygen species, soot, polycyclic aromatic compounds and allergenic proteins, Free Radical Res., 46, 927-939, https://doi.org/10.3109/10715762.2012.663084, 2012.

Verma, V., Rico-Martinez, R., Kotra, N., King, L., Liu, J., Snell, T. W., and Weber, R. J.: Contribution of water-soluble and insoluble components and their hydrophobic/hydrophilic subfractions to the reactive oxygen species-generating potential of fine ambient aerosols, Environ. Sci. Technol., 46, 11384-11392, https://doi.org/10.1021/es302484r, 2012.
Verma, V., Fang, T., Xu, L., Peltier, R. E., Russell, A. G., Ng, N. L., and Weber, R. J.: Organic aerosols associated with the generation of reactive oxygen species (ROS) by water-soluble $\mathrm{PM}_{2.5}$, Environ. Sci. Technol., 49, 4646-4656, https://doi.org/10.1021/es505577w, 2015a.

Verma, V., Wang, Y., El-Afifi, R., Fang, T., Rowland, J., Russell, A. G., and Weber, R. J.: Fractionating ambient humic-like substances (HULIS) for their reactive oxygen species activity - Assessing the importance of quinones and atmospheric aging, Atmos. Environ., 120, 351-359, https://doi.org/10.1016/j.atmosenv.2015.09.010, 2015b.

Wang, Y., Hopke, P. K., Sun, L., Chalupa, D. C., and Utell, M. J.: Laboratory and field testing of an automated atmospheric particle-bound reactive oxygen species sampling-analysis system, J. Toxicol., 2011, 419476, https://doi.org/10.1155/2011/419476, 2011.

Wilson, J. G., Kingham, S., Pearce, J., and Sturman, A. P.: A review of intraurban variations in particulate air pollution: Implications for epidemiological research, Atmos. Environ., 39, 6444-6462, https://doi.org/10.1016/j.atmosenv.2005.07.030, 2005.

$\mathrm{Xu}$, L., Suresh, S., Guo, H., Weber, R. J., and Ng, N. L.: Aerosol characterization over the southeastern United States using high-resolution aerosol mass spectrometry: spatial and seasonal variation of aerosol composition and sources with a focus on organic nitrates, Atmos. Chem. Phys., 15, 7307-7336, https://doi.org/10.5194/acp-15-7307-2015, 2015.

Yang, A., Jedynska, A., Hellack, B., Kooter, I., Hoek, G., Brunekreef, B., Kuhlbusch, T. A. J., Cassee, F. R., and Janssen, N. A. H.: Measurement of the oxidative potential of $\mathrm{PM}_{2.5}$ and its constituents: The effect of extraction solvent and filter type, Atmos. Environ., 83, 35-42, https://doi.org/10.1016/j.atmosenv.2013.10.049, 2014.

Yang, A., Janssen, N. A. H., Brunekreef, B., Cassee, F. R., Hoek, G., and Gehring, U.: Children's respiratory health and oxidative potential of $\mathrm{PM}_{2.5}$ : the PIAMA birth cohort study, Occup. Environ. Med., 73, 154-160, https://doi.org/10.1136/oemed-2015103175, 2016 